The origin of the uniaxial anisotropy remains a largely unsolved problem. All these, together with an extensive treatment of the nature and dynamies of the magnetization reversal, are discussed by the author with admirable clarity and detail.

Almost all the work described refers to nickel-iron alloys containing about 80 per cent nickel. The feeling that the lack of real progress in understanding is due, at least in part, to the narrowness of the frontal assault is, to some extent, confirmed by the final chapter which discusses the spontaneous magnetization of thin films. The predietion that a two-dimensional lattice should be paramagnetic and exhibit spontaneous magnetization only when a critical thickness is exceeded is a common feature of many theories. Experiments on iron and nickel fail to confirm the predicted thickness dependences but reveal the presence of an oxide layer 4-8 $\AA$ thick even when the film is prepared and studied at a pressure of $10^{-9} \mathrm{~mm}$ mercury. Irreversible oxidation of ultra-thin films of iron occurs immediately they are exposed to air. Since nickel-iron films are usually prepared at pressures of about $10^{-5} \mathrm{~mm}$ mercury it is likely that many of them contain considerable amounts of oxygen and, to judge from results quoted elsewhere in Thin Ferromagnetic Films, significant quantities of crucible material as well. The implication is that many physicists have, unwittingly, studied in great detail the properties of they know not what.

The whole of this book is welcome, but the final chapter with its implied cautionary warning should be compulsory reading for all those engaged in the manufacture, study and application of ferromagnetic thin films.

E. W. LEE

\section{POLLUTION OF THE THAMES ESTUARY}

Effects of Polluting Discharges on the Thames Estuary (Department of Scientific and Industrial Research. Water Pollution Research Technical Paper, No. 11.) The Reports of the Thames Survey Committee and the Water Pollution Research Laboratory. Pp. xxviii $+609+24$ plates. (London: H.M.S.O., 1964.) $252 s$.

$\mathrm{T}$ HE use of mathematical models to assist in the management of water resources has developed greatly in the past decade. Undoubtedly high-speed electronic computers have played a great part in this development, as hitherto unmanageable or tedious problems held back this form of study and control.

This has been true in the study of the effects of polluting discharges on the Thames estuary, the report of which has been recently published following fourteon years of work. In the earlier years covered by the Report calculations were made but the number of variables that could be studied was restricted. In the later years, however, more sophisticated mathematical models could be handled by the electronic computers of the National Physical Laboratory.

The greater part of the scientific work was carried out by the staff of the Water Pollution Research Laboratory (although with significant assistance by the London County Council, the Port of London Authority and a number of other organizations involved with the Thames). A theory of estuarine mixing, without stratification, was evolved, the resulting equations describing the salinity distributions along the estuary. As the freshwater flow changed in the river, so the salinity distribution changes were calculated, and theoretical curves showed a close correlation with observed data.

These considerations of the distribution of a conservative (that is, not created or destroyed in the water) substance sodium chloride, led on to the more difficult problems associated with non-conservative substances, for example, ammonia, dissolved oxygen, temperature. Over a period of a whole number of tidal intervals the concentration distribution may change due to increases from land discharges, decreases due to dilutions, loss from the water, conversions from or to other substances, seaward displacement due to land-water flow and mixing of the estuarine water. These factors have been considered particularly for the case of dissolved oxygen and associated substances. For this a number of assumptions were made, principally that the rate of oxidation of organic carbon is independent of the dissolved oxygen concentration, that the rate of nitrification is proportional to the ammonia concentration except where the dissolved oxygen would fall to 5 per cent saturation, that nitrate reduction supplies the oxygen when the dissolved oxygen is at 5 per cent saturation, and that when nitrate and dissolved oxygen are absent reduction of sulphate supplies the required oxygen.

As temperature affects these oxidation and reduction rates, as well as the solution of oxygen in water, the distribution of temperature, mainly affected by heated discharges from power stations, has also been considered. Also some of the oxidizable material is in suspension and deposition of such solids diminishes the polluting load.

Using the mathematical models developed from these various considerations, the distributions along seventy miles of the estuary of the concentrations of dissolved oxygen, ammoniacal nitrogen and oxidized nitrogen, have been calculated for every quarter of the years 1950 to 1961. With regard to dissolved oxygen, these correlated well with the values observed by the London County Council. Some of the ammoniacal nitrogen curves were at variance with observation, particularly in the third quarter of a number of years, and there were some marked discrepancies between some first quarter calculated and observed values for oxidized nitrogen. Some of these discrepancies were due to the assumption that the oxygen exchange coefficient was constant along the estuary. This assumption was examined in the Report and the effects of a varying exchange coefficient have been calculated. However, as there was no way of assessing the variations of this coefficient with time and position, no attempt was made to use this as a variable. Another source of error was thought to be due to reduction of nitrate in mud deposits, in spite of the presence of substantial amounts of dissolved oxygen in the water.

The condition of the Thames estuary has been deteriorating for several decades, although previously the treatment or partial treatment of sewage had ameliorated the worst effects of the Industrial Revolution. By the 1950's anaerobic conditions became frequent and extensive, with production of sulphide, causing offensive odour and marked adverse effects on paint and metal surfaces. With the mathematical models now available the factors which may ameliorate these conditions can be assessed rationally. A number of these have been assessed in the Report, such as the relocation of the London County Council's sewage treatment works lower on the estuary, and changing the minimum freshwater flow of the Thames, and removal of synthetic detergent residues. An attempt has even been made to determine the conditions necessary to restore the Thames to being a salmon river, although this does not appear to be a likely possibility.

Considering the great complexity of the Thames estuary, amply illustrated both by the text and the photographs in the Report, it is an outstanding achievement to have produced such a comprehensive and coherent account of the effects of pollution, and to have provided such useful tools for its future management. This carefully documented Report will serve as a model and a guide for similar studies the world over. K. J. Ives 